\title{
Evaluasi Simpang Tiga pada Jalan Jendral Sudirman Kuala Tungkal
}

\author{
Ardiansyah*, Amsori M. Das, Ari Setiawan \\ Program Studi Teknik Sipil Universitas Batanghari Jambi \\ *Correspondence email: Ardiiiahmad@gmail.com
}

\begin{abstract}
Abstrak. Dalam menunjang kelancaran transportasi pada daerah urban khususnya transportasi darat, dibutuhkan sarana dan prasarana yang mendukung. Tingginya jumlah transportasi nasional khususnya kendaraan bermotor pertahun mencapai $6,13 \%$ (BPS,2019). Dampak dari tingginya jumlah transportasi akan timbul ketika penambahan jumlah transportasi tidak diikuti dengan sarana dan prasarana yang memadai. Seperti adanya peningkatan arus lalu lintas yang tidak seimbang dikarenakan ketersediaan kapasitas jalan yang kecil. Tujuan dari penelitian ini adalah untuk mengevaluasi tingkat pelayanan lalu lintas pada ruas simpang tiga Jalan Jendral Sudirman Kuala Tungkal. Perhitungan kinerja simpang menggunakan Manual Kapasitas Jalan Indonesia (MKJI) 1997. Data yang didapat pada penelitian ini menggunakan metode survei yang dilaksanakan pada pagi sore dan malam hari selama dua hari. Hasil survei menunjukan kondisi eksisting menghasilkan (DS) derajat kejenuhan pada malam hari sebesar 0,84 dimana kondisi eksisting kinerja simpang sudah mencapai kondisi jenuh.
\end{abstract}

Kata Kunci: Simpang Bersinyal; MKJI 1997; Derajat Kejenuhan; Tundaan

\section{PENDAHULUAN}

Badan Pusat Statistik memperkirakan angka urbanisasi pertahun dapat mencapai 2,3\% dengan jumlah penduduk lebih dari 55\% berada di perkotaan (BPS,2018). Kuala Tungkal adalah ibu kota dari Kabupaten Tanjung Jabung Barat Provinsi Jambi terletak di kecamatan tungkal ilir, yang merupakan daerah urban dikarenakan menjadi pusat daerah perekonomian dan pemerintahan. Perkembangan kota akan mendorong adanya pembangunan infrastruktur jalan dan penyediaan transportasi demi menunjang aktivitas-aktivitas masyarakat di kota tersebut (Tamara dan Sasana, 2016).

Transportasi merupakan salah satu aspek kehidupan yang mempunyai peranan sangat penting bagi daerah perdesaan, semi urban maupun daerah urban (Silondae, 2016). Dalam menunjang kelancaran transportasi pada daerah urban khususnya transportasi darat, dibutuhkan sarana dan prasarana yang mendukung. Sehingga dapat memudahkan manusia dalam melakukan perpindahan tempat untuk mencapai tujuan. Tingginya jumlah transportasi nasional khususnya kendaraan bermotor pertahun mencapai 6,13 \% (BPS,2019). Dampak dari tingginya jumlah transportasi akan timbul ketika penambahan jumlah transportasi tidak diikuti dengan sarana dan prasarana yang memadai. Seperti adanya peningkatan arus lalu lintas yang tidak seimbang dikarenakan ketersediaan kapasitas jalan yang kecil.

Menurut UU No 38 tahun 2004 tentang jalan, jalan adalah prasarana transportasi darat yang meliputi segala bagian jalan, termasuk bangunan pelengkap dan perlengkapannya yang diperuntukkan bagi lalu-lintas. Salah satu jalan yang memiliki kepadatan yang tinggi yang terletak di kota Kuaka tungkal adalah Jalan Jendral Sudirman, jalan ini merupakan jalan menghubungkan antar jenjang kota. Adapun maksud dipilihnya lokasi penelitian ini, disebabkan karena tingkat kepadatan kendaraan yang semakin tinggi terutama pada jam-jam sibuk. Tujuan penelitian ini adalah untuk mengevaluasi tingkat pelayanan lalu lintas pada ruas simpang tiga Jalan Jendral Sudirman Kuala Tungkal.

\section{METODE}

Metode yang digunakan pada penelitian ini adalah survei. Menurut Asep (2009) dalam Novianti dan Qomariah (2017), Penelitian survei terdiri dari cross sectional dan longitudenal. Cross sectional adalah penelitian sekali bidik (one snapshot), dimana pengumpulan datanya dilakukan pada suatu titik waktu tertentu. Adapun data yang dibutuhkan pada penelitian ini adalah data primer dan data sekunder. Data primer berupa survei geometri jalan dan volume lalu lintas. Data diperoleh dari pemerintahan yaitu dinas perhubungan Kabupaten Tanjung Jabung Barat untuk mendapatkan data lalu lintas harian rata-rata dan Dinas Dukcapil Kabupaten Tanjung Jabung Barat untuk mendapatkan jumlah pertumbuhan penduduk selama 3 tahun tahun terakhir.

Pelaksanaan survei dilaksanakan pada hari minggu, dan hari senin, dengan waktu selama 2 jam yang dibagi menjadi 3 periode waktu. Pengamatan jam sibuk pada pagi hari dilakukan dari pukul 07.00 - 09.00, waktu pengamatan jam sibuk sore dari pukul 16.00 - 18.00, kemudian pada waktu jam sibuk pada malam hari dilakukan dari pukul 19.00 - 21.00. Survei ini dilakukan oleh 6 orang tenaga survei. Adapun alat yang dibutuhkan dalam melakukan penelitian ini sebagai berikut :

1. Roll meter, untuk mengukur geometrik jalan yang meliputi lebar jalan, lebar trotoar jalan dan bahu jalan.

2. Alat tulis seperti kertas hvs, pena, pensil, dan penggaris, untuk mencatat data penelitian.

3. Formulir survei volume kendaraan dan kecepatan rata-rata kendaraan, dimana formulir survei sebagaimana terlampir. 
4. Alat penghitung (handy tally counter), untuk menghitung jumlah kendaraan yang melewati jalan dalam kurun waktu yang sudah ditentukan

5. Stopwatch atau alat pengukur waktu dengan ketelitian 1/100 detik, dipergunakan untuk menghitung kecepatan ratarata.

6. Jam tangan dipergunakan untuk menghitung ataupun mengukur periode waktu pengumpulan data dengan interval waktu per 15 menit selama pelaksanaan survei.

7. Kamera sebagai alat untuk mendokumentasikan segala kegiatan dan kondisi dilapangan.

\section{HASIL DAN PEMBAHASAN \\ Kondisi Geometrik}

Perlu pemahaman kondisi awal kawasan simpang untuk mengidentifikasi permasalahan yang ada sehingga analisis dapat menghasilkan kondisi yang berguna bagi kawasan saat ini dan di masa yang akan datang. Gambar di bawah menunjukkan geometri simpang pada kondisi eksisting.

Gambar 1. Geometrik pendekat simpang

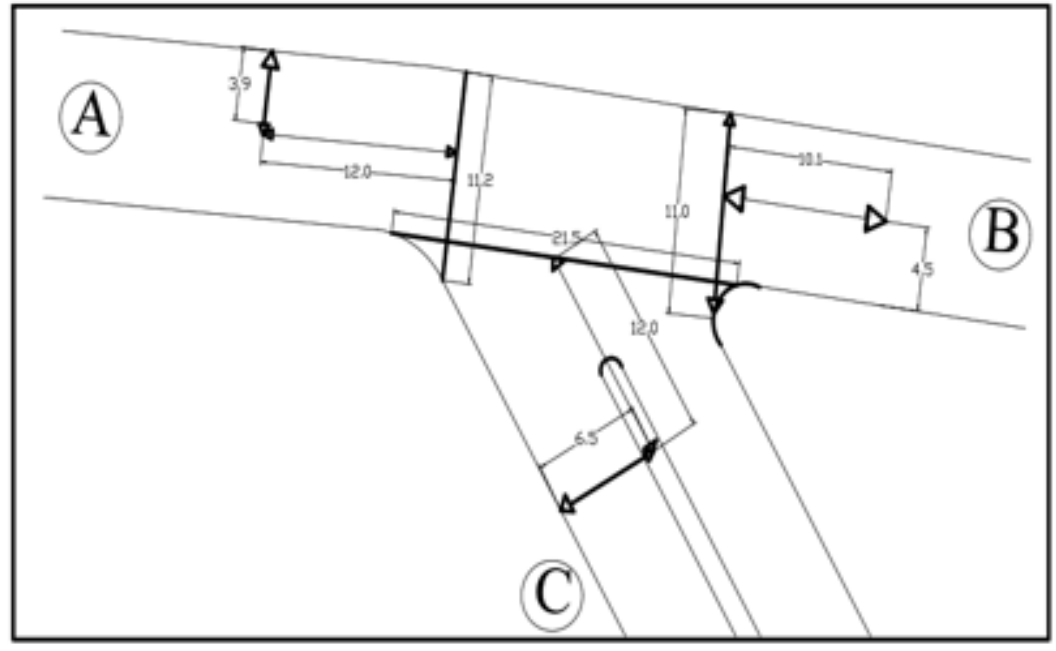

Sumber: Data olahan 2020

Gambar 2. Geometrik ruas Jalan Jendral Sudirman

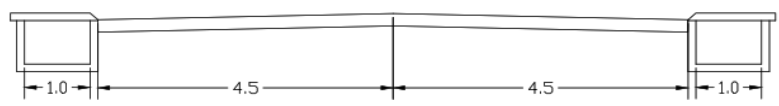

Sumber: Data olahan 2020

Gambar 3. Geometrik ruas Jalan Prof. Sri Soedewi

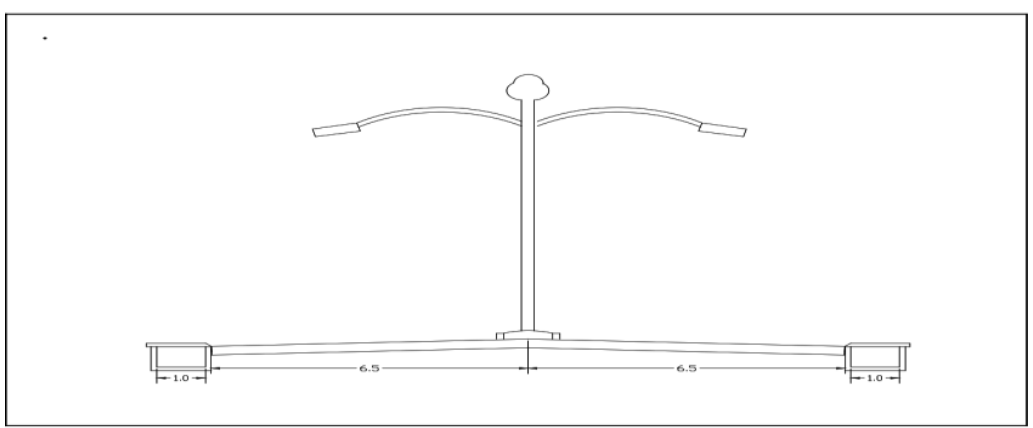

Sumbar: Data olahan 2020

Data Volume Lalu Lintas 
Volume arus lalu lintas didapat dari hasil survei lapangan yang dilakukan dengan interval waktu 15 menit selama 2 jam. Hasil survei harus dijumlahkan terlebih dahulu untuk masing-masing jenis kendaraan dan masingmasing arah pergerakan, sehingga diperoleh nilai total arus lalu lintas.

Untuk memperoleh arus lalu lintas dalam kend/jam, maka jumlah arus dalam interval dijumlahkan sampai 1 jam, kemudian jumlah yang terbesar pada setiap periode waktu adalah jumlah arus lalu lintas dalam kend/jam. Kemudian dikalikan dengan ekivalen mobil penumpang (emp) masing-masing (HC, LV, dan MC) untuk mendapatkan arus dalam smp/jam. Nilai inilah yang menjadi volume jam puncak pada periode waktu pagi, sore, dan malam hari. Analisis data berpedoman pada MKJI, 1997.

\section{Kapasitas}

Kapasitas total untuk seluruh lengan simpang adalah hasil perkalian antara kapasitas dasar $\left(\mathrm{C}_{0}\right)$, yaitu kapasitas pada kondisi tertentu (ideal) dan faktor-faktor penyesuaian (F), dengan memperhitungkan pengaruh kondisi lapangan terhadap kapasitas.

Adapun Bentuk model kapasitas adalah sebagai berikut:

\section{$\mathrm{C}=\mathrm{C}_{0} \times \mathbf{F}_{\mathrm{W}} \times \mathbf{F}_{\mathrm{M}} \times \mathbf{F}_{\mathrm{CS}} \times \mathbf{F}_{\mathrm{RSU}} \times \mathbf{F}_{\mathrm{LT}} \times \mathbf{F}_{\mathrm{RT}} \times \mathbf{F}_{\mathrm{MI}}$}

Dimana:

C : Kapasitas

Co $\quad$ : Kapasitas Dasar (smp/jam)

$\mathrm{F}_{\mathrm{W}} \quad$ : Faktor penyesuaian lebar masuk

$\mathrm{F}_{\mathrm{M}} \quad$ : Faktor penyesuaian median jalan utama

$\mathrm{F}_{\mathrm{CS}} \quad$ : Faktor penyesuaian ukuran kota

$\mathrm{F}_{\mathrm{RSU}} \quad$ : Faktor penyesuaian tipe lingkungan jalan, hambatan samping,dan kendaraan tak bermotor

$\mathrm{F}_{\mathrm{LT}} \quad$ : Faktor penyesuaian belok kiri

$\mathrm{F}_{\mathrm{RT}} \quad$ : Faktor penyesuaian belok kanan

$\mathrm{F}_{\mathrm{MI}} \quad$ : Faktor penyesuaian rasio arus jalan minor

Tipe simpang pada penelitian ini adalah tipe 342 berdasarkan MKJI 1997 sehingga kapasitas dasarnya $\left(\mathrm{C}_{0}\right)$ adalah $2900 \mathrm{smp} / \mathrm{jam}$, seperti tabel berikut:

Tabel 1. Tipe simpang

Sumber: MKJI, 1997

\begin{tabular}{|cc|}
\hline Tipe simpang IT & Kapasitas dasar smp/jam \\
\hline 322 & 2700 \\
\hline 342 & 2900 \\
\hline 324 atau 344 & 3200 \\
422 & 2900 \\
424 atau 444 & 3400 \\
\hline
\end{tabular}

Faktor penyesuaian median jalan utama $\left(\mathrm{F}_{\mathrm{M}}\right)$ diperoleh dengan menggunkan tabel berikut ini. Penyesuaian hanya digunakan untuk jalan utama dengan 4 lajur.

Tabel 2. Faktor untuk penyesuaian median jalan utama

\begin{tabular}{ccc|}
\hline Ukuran Kota CS & Penduduk Juta & Faktor penyesuaian ukuran kota $\mathrm{F}_{\mathrm{CS}}$ \\
\hline Sangat kecil & $<0,1$ & 0,82 \\
\hline Kecil & $0,1-0,5$ & 0,88 \\
Sedang & $0,5-1,0$ & 0,94 \\
Besar & $1,0-3,0$ & 1,00 \\
Sangat besar & $>3,0$ & 1,05 \\
\hline
\end{tabular}

Sumber: MKJI, 1997

Berdasarkan hasil koordinasi dengan Dinas Dukcapil Kabupaten Tanjung Jabung Barat, jumlah penduduk Kabupaten Tanjung Jabung Barat pada tahun 2019 adalah 320,108 jiwa, maka ukuran kota dapat dikategorikan ukuran kota kecil dan $\mathrm{F}_{\mathrm{CS}}=0,88$ ditentukan dari tabel dibawah: 
Tabel 3. Faktor penyesuaian ukuran kota $\left(\mathrm{F}_{\mathrm{CS}}\right)$

Sumber: MKJI,1997

\begin{tabular}{|ccc|}
\hline Uraian & Tipe $\mathrm{M}$ & Faktor Penyesuaian Median $\left(\mathrm{F}_{\mathrm{M}}\right)$ \\
\hline Tidak ada median jalan utama & Tidak ada & 1,00 \\
\hline Ada median jalan utama, lebar $\geq 3 \mathrm{~m}$ & Sempit & 1,05 \\
Ada median jalan utama, lebar $\geq 3 \mathrm{~m}$ & Lebar & 1,20 \\
\hline
\end{tabular}

\section{Pembahasan}

\section{Perhitungan Data}

$\mathrm{W}_{\mathrm{AC}} \quad=\mathrm{c}=6.5$

$\mathrm{W}_{\mathrm{BD}} \quad=\frac{\mathrm{b}+\mathrm{d}}{2}=\frac{4,5+4,5}{2}=4,5$

$\mathrm{W}_{1}=(\mathrm{b}+\mathrm{c}+\mathrm{d}) / 3=(4,5+4,5+6,5) / 3=5,16 \mathrm{~m}$

$\mathrm{F}_{\mathrm{W}} \quad=0,67+0,0698 * \mathrm{~W}_{1}$

$=0,67+0,0760 * 4,5$

$=1,03$

$\mathrm{F}_{\mathrm{M}} \quad=1$ untuk tanpa median pada jalan utama

$\mathrm{F}_{\mathrm{CS}} \quad=0,88$ untuk ukuran kota kecil

$\mathrm{F}_{\mathrm{RSU}} \quad=0,89$ untuk tipe lingkungan komersil dengan hambatan samping sedang

$\mathrm{P}_{\mathrm{LT}} \quad=\mathrm{Q}_{\mathrm{LT}} / \mathrm{Q}_{\mathrm{TOT}}$

Dimana:

$\mathrm{P}_{\mathrm{LT}} \quad$ : Rasio belok kiri

QtT : Arus belok kiri

$\mathrm{Q}_{\text {тот }}$ : Arus total

$\mathrm{P}_{\mathrm{LT}} \quad$ : Rasio belok kiri

Qтот : Arus Total

Pagi $\quad: \mathrm{P}_{\mathrm{LT}}=473,2 / 1193,6=0,40$

Sore $\quad: \mathrm{P}_{\mathrm{LT}}=316 / 1191,2=0,27$

Malam : $\mathrm{P}_{\mathrm{LT}}=467,6 / 1999,2=0,23$

$\mathrm{F}_{\mathrm{LT}}=0,84+1,61 \mathrm{P}_{\mathrm{LT}}$

$\mathrm{F}_{\mathrm{LT}}=1,48$ (Pagi), 1,29 (Sore), 1,24 (Malam)

$\mathrm{P}_{\mathrm{RT}}=\mathrm{Q}_{\mathrm{RT}} / \mathrm{Q}_{\mathrm{TOT}}$

Dimana:

$\mathrm{P}_{\mathrm{RT}} \quad$ : Rasio belok kanan

$\mathrm{Q}_{\mathrm{RT}} \quad$ : Arus belok kanan

$\mathrm{Q}_{\text {тот }}$ : Arus total

Pagi : $350,4 / 1193=0,29$

Sore $: 262 / 1193,6=0,22$

Malam : 459,6/1999,2 $=0,23$

$\mathrm{F}_{\mathrm{RT}} \quad=1,09-0922 \mathrm{P}_{\mathrm{RT}}$

$\mathrm{F}_{\mathrm{RT}} \quad=0,82$ (Pagi), 0,89 (Sore), 0,88 (Malam)

$\mathrm{P}_{\mathrm{MI}}=\mathrm{Q}_{\text {MI }} / \mathrm{Q}_{\text {Tот }}$

Dimana:

$\mathrm{P}_{\mathrm{MI}} \quad$ : Rasio jalur minor

$\mathrm{Q}_{\mathrm{MI}} \quad$ : Arus jalur minor

Qтот : Arus total

Pagi $\quad: 296 / 1193,6=0,24$

Sore $: 258 / 1191,2=0,22$

Malam : 474,8/1999,2 =0,25

$\mathrm{F}_{\mathrm{MI}} \quad=1,19 * \mathrm{P}_{\mathrm{MI}}^{2}-1,19 * \mathrm{P}_{\mathrm{MI}}+1,19$

$\mathrm{F}_{\mathrm{MI}}=0,93$ (Pagi), 0,95 (Sore), 0,93 (Malam)

Dengan nilai-nilai tersebut maka didapatkan nilai kapasitas sebagai berikut:

$\mathbf{C}=\mathbf{C}_{\mathbf{0}} * \mathbf{F}_{\mathrm{W}} * \mathbf{F}_{\mathbf{M}} * \mathbf{F}_{\mathbf{C S}} * \mathbf{F}_{\mathbf{R S U}} * \mathbf{F}_{\mathbf{L T}} * \mathbf{F}_{\mathbf{R T}} * \mathbf{F}_{\mathbf{M I}}$

$\mathrm{C}($ Pagi $) \quad=2900 * 1,03 * 1 * 0,88 * 0,89 * 1,48 * 0,82 * 0,93$ 


$$
\begin{aligned}
& =2640,38 \mathrm{smp} / \mathrm{jam} \\
\mathrm{C}(\text { Sore }) & =2900 * 1,03 * 1 * 0,88 * 0,89 * 1,29 * 0,89 * 0,95 \\
& =2551,59 \mathrm{smp} / \mathrm{det} \\
\mathrm{C}(\text { Siang }) & =2900 * 1,03 * 1 * 0,88 * 0,89 * 1,24 * 0,88 * 0,93 \\
& =2374,08 \mathrm{smp} / \mathrm{jam}
\end{aligned}
$$

\section{Derajat Kejenuhan}

Derajat kejenuhan untuk seluruh simpang, (DS), dihitung sebagai berikut:

DS $=\frac{\text { QTOT }}{\text { C }}$

Dimana:

$\mathrm{Q}_{\text {Tот }}=$ Arus total $(\mathrm{smp} / \mathrm{jam})$

$\mathrm{C} \quad=$ Kapasitas $(\mathrm{smp} / \mathrm{jam})$

Maka dengan nilai-nilai tersebut maka derajat kejenuhan pada setiap ruas simpang sebagai berikut:

$$
\begin{array}{ll}
\text { DS }(\text { Pagi }) & =\frac{1193,6}{2640,38}=0,45 \\
\text { DS }(\text { Sore }) & =\frac{1191,2}{2551,59}=0,47 \\
\text { DS (Malam) } & =\frac{1999,2}{2374,08}=0,84
\end{array}
$$

\section{Tundaan lalu lintas}

\section{Tundaan lalu lintas simpang}

$$
\begin{array}{ll}
\mathbf{D T}_{\mathbf{I}} & =\mathbf{2 + 8 , 2 0 7 8} * \mathbf{D S}-(\mathbf{1 - D S}) * \mathbf{2} \text { untuk DS }<=0,6 \\
\mathbf{D T}_{\mathbf{I}} & =\mathbf{1 , 0 5 0 4} /(\mathbf{0 , 2 4 7 - 0 , 2 0 4 2} * \mathbf{D S})-(\mathbf{1 - D S}) * \mathbf{2} \text { untuk DS }>0,6 \\
\mathrm{DT}_{\mathrm{I}}(\text { Pagi }) & =2+8,2078 * 0,45-(1-0,45) * 2 \\
& =4,59 \mathrm{det} / \mathrm{smp} \\
\mathrm{DT}_{\mathrm{I}}(\text { Sore }) & =2+8,2078 * 0,47-(1-0,47) * 2 \\
& =4,80 \\
\mathrm{DT}_{\text {I }}(\text { Malam }) & =1,0504 /(0,2742-0,2042 * 0,84)-(1-0,84) * 2 \\
& =9,91 \mathrm{det} / \mathrm{smp}
\end{array}
$$

\section{Tundaan lalu lintas jalan utama}

$$
\begin{aligned}
& \text { DT }_{\text {MA }}=\mathbf{1 , 8 + 5 , 8 2 3 4} * \text { DS-(1-DS) } * 1,8 \text { untuk DS }<=0,6 \\
& \text { DT }_{\text {MA }} \quad=\mathbf{1 , 0 5 0 3 4} /(\mathbf{0 , 3 4 6 - 0 , 2 4 6} * \mathrm{DS})-(\mathbf{1}-\mathrm{DS}) * \mathbf{1}, \mathbf{8} \text { untuk DS }>0,6 \\
& \mathrm{DT}_{\mathrm{MA}}(\text { Pagi) } \quad=1,8+5,8234 * 0,45-(1-0,45) * 1,8 \\
& =3,43 \mathrm{det} / \mathrm{smp} \\
& \mathrm{DT}_{\mathrm{MA}} \text { (Sore) } \quad=1,8+5,8234 * 0,47-(1-0,47) * 1,8 \\
& =3,58 \mathrm{det} / \mathrm{smp} \\
& \mathrm{DT}_{\mathrm{MA}}(\text { Malam })=1,05034 /(0,346-0,246 * 0,84)-(1-0,84) * 1,8 \\
& =7,25 \mathrm{det} / \mathrm{smp}
\end{aligned}
$$

\section{Tundaan lalu lintas jalan minor}

$$
\begin{aligned}
\mathbf{D T}_{\mathbf{M I}} & =\left(\mathbf{Q}_{\mathbf{T O T}^{*}} * \mathbf{D T} \mathbf{T}_{\mathbf{I}}-\mathbf{Q}_{\mathbf{M A}} * \mathbf{D T} \mathbf{T}_{\mathbf{M A}}\right) / \mathbf{Q}_{\mathbf{M I}} \\
\mathrm{DT}_{\mathrm{MI}}(\text { Pagi }) & =(1193,6 * 4,59-897,6 * 3,43) / 296 \\
& =8,11 \mathrm{det} / \mathrm{smp} \\
\mathrm{DT}_{\mathrm{MI}}(\text { Sore }) & =(1191,2 * 4,8-933,2 * 3,58) / 258 \\
& =9,21 \mathrm{det} / \mathrm{smp} \\
\mathrm{DT}_{\mathrm{MI}}(\text { Malam }) & =(1999,2 * 9,91-1524,4 * 7,25) / 474,8 \\
& =18,45 \mathrm{det} / \mathrm{smp}
\end{aligned}
$$

$$
\begin{aligned}
& \text { Tundaan geometrik simpang } \\
& \begin{aligned}
\text { DG } & =(\mathbf{1}-\mathbf{D S}) *\left(\mathbf{P}_{\mathrm{T}}^{*} \mathbf{6}+\left(\mathbf{1}-\mathbf{P}_{\mathrm{T}}\right) * \mathbf{3}\right)+\mathbf{D S} * \mathbf{4} \text { untuk DS }<1,0 \\
& =(1-0,45) *(823,6 * 6+(1-823,6) * 3)+0,45 * 4 \\
\text { DG }(\text { Pagi }) & =1362,39 \mathrm{det} / \mathrm{smp} \\
\text { DG }(\text { Sore }) & =(1-0,47) *(578 * 6+(1-578) * 3)+0,47 * 4 \\
& =922,49 \mathrm{det} / \mathrm{smp}
\end{aligned}
\end{aligned}
$$




$$
\begin{aligned}
\text { DG }(\text { Malam }) & =(1-0,84) *(927,2 * 6+(1-927,2) * 3)+0,84 * 4 \\
& =448,90 \mathrm{det} / \mathrm{smp}
\end{aligned}
$$

$$
\begin{array}{ll}
\text { Tundaan simpang } \\
\begin{array}{ll}
\mathbf{D} & =\mathbf{D G}+\mathbf{D T}_{\mathbf{I}} \\
\mathrm{D}(\text { Pagi }) & =1362,39+4,59 \\
& =1366,98 \mathrm{det} / \mathrm{smp} \\
\mathrm{D}(\text { Sore }) & =922,49+4,8 \\
& =927,29 \mathrm{det} / \mathrm{smp} \\
\mathrm{D}(\text { Malam }) & =448,9+9,91 \\
& =458,81 \mathrm{det} / \mathrm{smp}
\end{array}
\end{array}
$$

$$
\begin{aligned}
& \text { Peluang antiran (QP\%) } \\
& \mathrm{QP} \%=9,02 * \mathrm{DS}+20,66 * \mathrm{DS}^{2}+\mathbf{1 0 , 4 9} * \mathrm{DS}^{3} \text { untuk batas bawah } \\
& \text { QP\% } \quad=47,71 * \text { DS-24,68*DS }{ }^{2}+56,47 * \text { DS }^{3} \text { untuk batas atas } \\
& \mathrm{QP} \% \text { (Bawah) }=9,02 * 0,45+20,66 * 0,45^{2}+10,49 * 0,45^{3} \\
& \mathrm{QP} \% \text { (Atas) }=47,71 * 0,45-24,68 * 0,45^{2}+56,47 * 0,45^{3} \\
& =9,20 \%-21,62 \% \text { untuk peluang antrian pagi } \\
& \mathrm{QP} \%(\text { Bawah })=9,02 * 0,47+20,66 * 0,47^{2}+10,49 * 0,47^{3} \\
& \mathrm{QP} \% \text { (Atas) }=47,71 * 0,47-24,68 * 0,47^{2}+56,47 * 0,47^{3} \\
& =9,98 \%-22,83 \% \text { untuk peluang antrian sore } \\
& \mathrm{QP} \%(\text { Bawah })=9,02 * 0,84+20,66 * 0,84^{2}+10,49 * 0,84^{3} \\
& \mathrm{QP} \% \text { (Atas) }=47,71 * 0,84-24,68 * 0,84^{2}+56,47 * 0,84^{3} \\
& =28,37 \%-56,13 \% \text { untuk peluang antrian malam }
\end{aligned}
$$

\section{Rekapitulasi Analisa}

Dari hasil hasil penelitian dan perhitungan maka rekapituasi analisa kondisi eksisting tahun 2020 dapat dilihat pada tabel dibawah ini:

Tabel 4. Tabel Rekapitulasi

\begin{tabular}{ccccc}
\hline \multirow{2}{*}{ Puncak } & $\begin{array}{c}\text { Kapasitas (C) } \\
\text { smp/jam }\end{array}$ & $\begin{array}{c}\text { Derajat Kejenuhan } \\
\text { (DS) }\end{array}$ & $\begin{array}{c}\text { Tundaan Simpang } \\
(\mathbf{Q P} \%)\end{array}$ & $\begin{array}{c}\text { Peluang Antrian } \\
(\mathbf{D}) \text { det/smp }\end{array}$ \\
\hline PAGI & 2640,38 & 0,45 & 1366,98 & $9,20 \%-22,83$ \\
SORE & 2551,59 & 0,47 & 927,29 & $9,98 \%-22,83 \%$ \\
MALAM & 2374,08 & 0,84 & 458,81 & $28,37 \%-56,13 \%$ \\
\hline
\end{tabular}

Sumber: Data olahan 2020

\section{SIMPULAN}

Berdasarkan dari hasil penelitian, perhitungan, dan pembahasan tugas akhir yang diperoleh, maka sebagai kesimpulan dari tugas akhir ini adalah sebagai berikut:

1. Derajat kejenuhan pada pagi hari 0,45 pada sore hari 0,47 dan pada malam hari 0,84 , maka dapat disimpulkan bahwa pada saat malam hari kondisi eksisting kinerja simpang sudah mecapai kondisi jenuh, dengan hasil perhitungan derajat kejenuhan sebesar DS 0,84.

2. Adapun peluang antrian berdasarkan hasil perhitungan, tingkat tertinggi berada dimalam hari yaitu sebesar $28,37 \%$ $-56,17 \%$.

\section{Saran}

Adapun beberapa saran yang perlu diperhatikan dalam memecahkan masalah evaluasi simpang tiga pada ruas simpang Jalan Jendral Sudirman Kuala Tungkal adalah sebagai berikut:

1. Memindahkan atau mentertibkan pedagang kaki lima di kawasan simpang tiga Jalan Jendral Sudirman Kuala Tungkal, agar trotoar dapat digunakan untuk pejalan kaki dan bahu jalan tidak dimanfaatkan untuk parkir kendaraan.

2. Bagi pemerintah sebaiknya perlu mensosialisasikan kepada masyarakat tentang tertib lalu lintas dan penggunaaan ruas jalan yang baik.

\section{DAFTAR PUSTAKA}

BPS, Bappenas, UNFPA. 2013. Proyeksi Penduduk Indonesia Indonesia Population Projection 2010-2035. Jakarta. BPS 
BPS. 2019. Statitik Transportasi Darat Land Transportation Statistics.Jakarta. BPS

Direktorat Jendal Bina Marga, P.T Bina Karya (Persero).1997. Manual Kapasitas Jalan Indonesia (MKJI).

Nofianti, L. Qomariah. 2017. Metode Penelitian survey. Fakultas ekonomi dan ilmu sosial UIN suska Riau.

Silondae, Sutami. 2016. Keterkaitan jalur transportasi dan interaksi ekonomi kabupaten konawe utara dengan kabupaten/kota sekitarnya. Jurnal progres ekonomi pembangunan vol.1.no.1. universitas halu oleo. Kendari.

Tamara, Sasana, Hadi.2016. Analisis Dampak Ekonomi Dan Sosial Akibat Kemacetan Lalu Lintas Di Jalan Raya Bogor-Jakarta. Jurnal riset ekonomi pembangunan vol.2.no.2. Fakultas ekonomi dan bisnis Universitas Diponegoro.

Undang-Undang Nomor 38 tahun 2004 tentang jalan. 